Article

\title{
With whom are you dealing? Using social network analysis as a tool to strengthen service delivery structures for low socioeconomic status populations
}

\author{
Lotte Prevo, ${ }^{1}$ Liesbeth Mercken, ${ }^{1}$ Maria Jansen, ${ }^{2}$ Stef Kremers ${ }^{1}$ \\ ${ }^{1}$ Department of Health Promotion, Maastricht University; ${ }^{2}$ Department of Health Services Research, \\ Maastricht University; Academic Collaborative Centre for Public Health, Public Health Service Southern \\ Limburg, Heerlen, The Netherlands
}

\begin{abstract}
Significance for public health
Although intervention programs to decrease health disparities between populations with different socioeconomic status (SES) are in place, low-SES individuals seem to experience barriers to participate. The daily issues they face related to being poor devote most of their mental energy, leaving no cognitive attention to any other health promoting goals to act upon. To enable these populations to improve their health, professionals should support them individually and help them in making optimal use of the available services to improve their situation. By fulfilling their basic needs, opportunities arise to enhance their health status. Currently professionals struggle to make optimal use of synergy and referral to relevant care, being unable to fulfil the basic needs of low-SES populations. This study gained more insight in the current network among low-SES families by using social network analysis, where this analysis was used as a tool to improve service delivery structures.
\end{abstract}

\footnotetext{
Abstract

Background: Health disparities between populations with different socioeconomic status (SES) are increasing. Although a wide variety of support service organizations and arrangements are in place, no general overview of this social network, its reach, and harmonization of services surrounding low-SES populations are available. The present participatory health research study examined the current network structure and the utility of using social network analysis (SNA) as a tool to improve service delivery structures.

Design and methods: We applied a mixed-methods study design. An online-questionnaire was used to examine the relationships among organizations assumed to support low-SES individuals in the municipality of Vaals, the Netherlands. In addition, semi-structured interviews and a networking session were used to examine the current network structure and to explore opportunities for improvement.

Results: The SNA revealed a weak network structure, and all interviewed professionals mentioned that the current structure should be improved. Participants indicated that a first step would be to install a central information system.

Conclusions: SNA can be a useful tool to gain more in-depth insights into the relations within a service delivery network. The professionals were assisted in discovering new organizations that could help them reach low SES populations and in harmonizing and improving their service delivery.
}

\section{Introduction}

Attempts to identify and reduce health disparities among populations with different socioeconomic status (SES) have been in place for many years. ${ }^{1-3}$ After the start of the economic crisis in 2008, the absolute numbers of people living in poverty increased, widening the gap between low-SES and middle- to high-SES populations. ${ }^{4}$ The impact has become visible especially in the United States, but also in European countries like the Netherlands. ${ }^{5-7}$ The low-SES population is characterized by the multiple problems they experience in the areas of finance, education, labour and/or health. ${ }^{3,8}$ Socially embedded problems lead to persistent socioeconomic health inequalities causing various negative effects on the lives of individuals. ${ }^{9}, 10$. Firstly, low-SES populations often experience the effects of economic disparities, leading to poverty situations, to which they have to devote a lot of their cognitive energy. This leads to higher stress levels and a tunnel vision focused on their financial difficulties. ${ }^{11}$ Secondly, the lower level of wealth due to a lower income has been associated with a poorer health status, including higher mortality and disability rates ${ }^{12-14}$ and unhealthy behaviours, like tobacco use, physical inactivity and poor nutrition. ${ }^{15}$ Thirdly, social disadvantages occur more frequently among low-SES populations, since people with a low-SES have been found to participate less in society and experience less social cohesion and support from people in their environment. ${ }^{16}$

In fact, these issues seem to be intergenerational, because children who grow up in poverty are likely to stay impoverished as adults. ${ }^{17}$ Research showed that childhood poverty caused significantly more psychological distress, antisocial behaviour, chronic physiological stress and short-term memory deficits later in life. ${ }^{17}$ Early interventions to provide support to low-SES families with children are becoming more important. ${ }^{3,17}$ Many formal and informal support services, aimed at various domains such as physical health, mental health and participation, are working to enhance the situation of these people, and various financial and other arrangements are present to improve their chances to participate in society. ${ }^{18}$ However, a clear overview of the support system surrounding low-SES populations is often lacking. This makes it difficult for low-SES people to find out how to make use of the different arrangements and support services in place. ${ }^{19}$ At the same time, professionals struggle to make optimal use of synergy and referral to relevant care, since some information is lacking about all the existing arrangements and organizations that they could refer to. ${ }^{19}$ Another difficulty is that low-SES individuals tend not to express their low-SES to others, to prevent being stigmatized. They are socalled hidden populations, difficult to reach by professionals. ${ }^{20}$

To ensure that low-SES populations can be reached and can 
make optimal use of the available support opportunities, it is important that local and regional professionals get to know each other, so as to be able to optimize referrals to each other and to contact each other about integration of different support services. ${ }^{18,20}$ Integrated tailored support plans are needed for each household to support them effectively, while taking account of the families' self-resilience. ${ }^{21}$ In practice, this requires that professionals coordinate their actions more to provide individually tailored services and to enhance the involvement of low-SES populations in their support plans..$^{21,22}$ Social network analysis (SNA) can be used as a tool to structure and visualize the relationships between organizations supporting low-SES populations, in order to evaluate the current network strength. ${ }^{23,24}$ SNA can conceptualize which professional organizations occupy a relatively central position within the support structures and can play a useful role in improving the network quality. ${ }^{25,26}$

This study examined the current network structure for service delivery to low-SES populations in the municipality of Vaals, the Netherlands. By involving the various stakeholders throughout the research process - from the processes of data collection to interpretation and dissemination - our participatory health research approach aimed to connect research with professional practice to help low-SES individuals. We identified potential members of the network by consulting the municipal authorities and the organizations involved. Subsequently, social network data were gathered among all potential stakeholders. Stakeholders who were in a relatively central position in the network took part in individual interviews to reflect on the results of the SNA and to identify opportunities to strengthen service delivery structures in the near future. As such, we studied the value of using network analysis as a tool to improve service delivery structures.

\section{Design and methods}

\section{Study design}

This mixed-methods study can be divided in three different phases. In phase 1 a social network analysis was used, with an online-questionnaire, to identify all the relationships among organizations that are supposed to provide services to low-SES individuals in the municipality of Vaals. The questions focused on their personal contacts with low-SES individuals and the organizations to which they referred them. After finishing phase 1, phase 2 started where we used a qualitative action research design with semistructured interviews to gain in-depth information about the current structure of the network organizations with regard to the support processes for low-SES populations. In addition, the diagram showing the network was discussed during the same interview, to explore the value of using network analysis as a discussion tool. We selected the most central organizations in the network, developed in phase 1, for the interviews. After the individual interviews, phase 3 started where we organized a networking session for professionals employed by the organizations that received the onlinequestionnaire to explain the overall findings, found in phase 1 and 2 , and to decide on a future strategy to strengthen the network.

\section{Study setting}

This study was carried out in the municipality of Vaals in the period from April 2017 to November 2017. This municipality is located in the southernmost part of the Netherlands, near the borders with Germany and Belgium, and can be characterized as moderate- to low-SES. ${ }^{27}$ One in seven families with children under the age of 18 living at home ( $\mathrm{N}=150$ households) in Vaals are living below the poverty line, which is about twice as many as the mean in the Netherlands. ${ }^{28}$ Moreover, residents have a poorer health status, a shorter life expectancy, more mental health issues, a less healthy lifestyle and more chronic diseases than the average population of the Netherlands. ${ }^{27}$

\section{Recruitment and study participants}

In April 2017, we compiled a list of 153 organizations assumed to have contacts with or support low-SES populations. This was done together with employees of the municipal authorities of Vaals, as the records of the social and health department already had a list of all organizations working in Vaals. On March 15, all of these organizations received an email explaining the purpose of the social network analysis. Subsequently, after being informed that the information was to be treated confidentially, the organizations that agreed to participate were included in the study, and the key employee of each organization, i.e. the one who knew most about current structures, was asked to fill in the questionnaire. The network analysis was carried out at the level of organizations (phase1). In October 2017, 17 key employees of the most central organizations in the network were approached for an individual interview, based on the results of the network analysis (phase 2). Finally, on November 21 a networking session was organized for key employees of all organizations that had participated in the network analysis (phase 3 ).

\section{Data collection procedure}

Emails with a link to the online questionnaire were sent to all organizations included in the list on March 15. Organizations that did not respond to this first email were reminded on March 22 and if they still did not respond, they were contacted by telephone in the period from March 29 till June 9. Based on the information gathered during the network analysis, semi-structured individual interviews were scheduled in October 2017 to gain in-depth information about the current service delivery structure for low-SES populations and to discover some recommendations to enhance the network structure in the future. Finally, in November 2017, a networking session was organized for all professionals employed by the organizations that participated in the network analysis, at which we prioritized the improvement mentioned as necessary during the interviews to enhance the quality of the network. In addition, the professionals were asked to select the main domain(s) their organization focused on, within the six domains of the concept of positive health, i.e. mental health, physical health, quality of life, giving meaning to life, participation and daily functioning. ${ }^{29}$ The aim was to provide the professionals with better insights into the functional domains of other organizations, which might give them ideas to strengthen the current network and set priorities.

\section{Data instruments and measures}

The network analysis used an online questionnaire, with three main questions. First, participants were asked if they had any contacts with people who were facing financial difficulties during the last month. Secondly, if their answer was affirmative, they were asked to state the total number of people with financial difficulties they had seen in the last month and how many of these were children or parents of children under the age of 18. Finally, if they had reported contacts with more than one person, they were asked to mention the organizations they had referred these people to. They were able to choose an unlimited number of organizations from our predefined list of organizations, and they had the possibility to add further organizations. The results were used to visualize the links between the organizations in a diagram with nodes depicting the 
organizations and ties showing the connections between them. The measures used for the data analysis were defined at network level and at organization level and can be found in Table $1 .^{30}$

The qualitative action research consisted of semi-structured interviews based on two main questions: 'How do you perceive the connections between professionals with regard to the service delivery for low-SES populations living in Vaals?' and 'How can we strengthen the connections within the network to enhance these support opportunities for low-SES populations?'. Halfway through the interview, the network that resulted from the SNA was shown and the questions about perceived connections between professional organizations and opportunities to strengthen the network were repeated to find out if the diagram had provided them with additional information. Finally, the results of the network analysis and interviews were presented during the networking session, and the professionals were asked to categorize themselves into the six domains of positive health defined by Huber. ${ }^{29}$ This helped the professionals get to know others working in the same domain and within other domains, ending in a discussion of the most important future strategy to strengthen the network.

\section{Data processing and analysis}

The results of the online questionnaire were entered into an Excel table, with 1 indicating a connection with an organization and 0 indicating that no connection was reported. This data file was imported in the UCINET 6 software package. ${ }^{31}$ Network level and organizational level network measures were calculated. To calculate the centrality measures the ties were undirected and the network was symmetrized using the maximum method. For the other measures, directed ties were used. The NetDraw 2.159 software was used to visualize the network. ${ }^{31}$ All organizations were categorized into 7 different types: municipal support organizations, e.g. the volunteer centre or the local intermediary who supports people in becoming socially and physically active; healthcare organizations e.g. general practices or mental health care, social support organizations, e.g. participation work organizations or the municipal credit bank; sports clubs, e.g. football or ballet clubs; recreational organizations, e.g. choirs or the library; educational organizations, e.g. schools or child day-care centres; and housing organizations, e.g. the housing corporation. In the visualization, the size of each node represented the scores on the degree of centrality.

In the qualitative action research, the individual interviews were recorded and transcribed verbatim. These transcripts were analysed in Excel. The analysis started with open coding in order to name and categorize elements in the interviewees' answers in terms of the predefined interview questions. These codes were used to discover similarities and differences between the interviewees' answers and eventually provided an overview of the perceived connections, which were used as input for the discussion about opportunities to strengthen the network in the networking session. During the networking session, notes were taken by the researcher, which were analysed to define potential consensus among stakeholders and priorities for strengthening the network.

\section{Results}

\section{Phase 1: Network analysis}

\section{Background information on organizations in the quantitative network analysis}

Of all 153 organizations that received the questionnaire, 95 (62\%) participated actively in the SNA. Of the 58 non-responding organizations $(38 \%), 7$ were mentioned by the responders as important partners to support the target group, which meant that at least some information was available about a total of 102 organizations. Most organizations were healthcare-oriented $(n=33$; $61.3 \%$ ), including general practices, physiotherapy practices and psychologists' practices. This was followed by recreational associations $(n=27 ; 66 \%)$, sports clubs $(n=21 ; 63.6 \%)$, and social service organizations $(\mathrm{n}=12 ; 70.5 \%)$. Only a few housing corporations $(n=2 ; 100 \%)$, educational organizations $(n=4 ; 80 \%)$ and municipal support organizations $(n=3 ; 100 \%)$ participated in the study, which

Table 1. Definitions of SNA measures.

\begin{tabular}{|c|c|}
\hline Measure & Description \\
\hline Degree of centralization & The extent to which ties within a network focus on one node or multiple nodes. \\
\hline Density & The number of the actual ties divided by the possible number of ties. \\
\hline Average degree & The mean number of ties of each of the nodes in the network. \\
\hline Components & $\begin{array}{l}\text { The maximum number of actors able to reach each other directly or indirectly } \\
\text { (each isolate, actor without a connection, is also considered to be a single component). }\end{array}$ \\
\hline Component ratio & The number of components relative to the total number of nodes in the network. \\
\hline Fragmentation \& Connectedness & The proportion of node pairs that are unreachable, while connectedness equals 1 - fragmentation. \\
\hline Dyad census & The number of node pairs having mutual, asymmetric or null ties. \\
\hline Reciprocity & The proportion of mutual ties relative to all ties. \\
\hline & Organizational level \\
\hline Raw in-degree & The degree of connections to other organizations in the network, also defined as the popularity of the node. \\
\hline Raw out-degree & The activity of the node in the network and thus the number of connections going out from the organization. \\
\hline Degree centrality & The interactions of one node with other nodes. \\
\hline Betweenness centrality & How often is a node on the shortest path between two other nodes. \\
\hline Average reciprocal distance & Direct or indirect reachability of other nodes while taking into account the distances. \\
\hline Eigenvector centrality & How close is a node to other nodes scoring high on centrality. \\
\hline
\end{tabular}

weak network structure, while for the other measures a score close to 0 shows a weak network structure. 
were relatively small groups. Most of the organizations were founded between the year 2000 and 2015 (58\%), while 36\% of them had started their work before the year 2000 and $6 \%$ had started working in Vaals in 2016. Of all participating organizations, almost $60 \%$ indicated that they had contacts with low-SES populations. Half of these organizations $(\mathrm{N}=28)$ mentioned being aware of and referring to other organizations in Vaals to reach and support the target group.

\section{Network measures for the complete network}

An overview of the network measures for the complete network can be found in Table 1. All included network measures indicated that the network had a weak structure. Organizations connected on average with fewer than one other organization within the network (average degree $=0.627$ ). The weak network structure is also indicated by the high component ratio and high number of isolates in the network $(\mathrm{N}=125)$. The network is highly fragmented and ties that exist are not reciprocal (Number of mutual ties $=0$ ).

\section{Network measures for each organization}

An overview of the network measures for each organization can be found in Table 3 . The 28 organizations with connections were ranked, from high to low, based on degree centrality. The other organizations can be defined as isolates that have no connections with other organizations in the network regarding the service delivery for low-SES citizens. Based on the in-degree and outdegree and the four centrality measures, especially healthcare, social support, and municipal support organizations, were most active within this network. Of all these types of organizations, the municipal support organizations and the housing organizations had no isolates, but they were also the smallest subgroups, with 3 organizations and 1 organization, respectively. Sports clubs had the highest percentage of isolates with $97 \%(\mathrm{~N}=32)$, followed by recreational organizations with $96 \%(\mathrm{~N}=48)$, educational organizations with $80 \%(\mathrm{~N}=4)$, healthcare organizations with $77 \%(\mathrm{~N}=34)$ and social support organizations with $41 \%(\mathrm{~N}=7)$. Figure 1 provides a visual overview of all independent organizations within the network. Figure 2 provides a visual overview of the connections between the different types of organizations within the network.

\section{Phase 2: Qualitative interviews using network analysis results to improve service delivery structures}

\section{Organizations participating in the qualitative interviews}

The qualitative interviews involved key employees representing the 17 most central organizations in the network. The following organizations were included: 3 municipal support organizations (local intermediary, sports coach, volunteer work), 1 recreational organization (library), 3 healthcare organizations (general practice, consultation office, mental health service), 5 social support organizations (municipal youth work, municipal social work, general social work, participation work organizations, municipal credit bank), 1 housing organization (housing corporation) and 4 educational organizations (child daycare, kindergarten, two primary schools). Of the interviewed professionals, 3 had already been employed before the year 2000, 12 had started working for the municipal authorities between 2000 and 2015, and 2 had started in the year 2017.

\section{The impact of network analysis as a professional conversation tool}

The use of the diagram (Figure 1) extended the interview time by 10 to 25 minutes. All 17 professionals mentioned that the dia-
Table 2. Network measures.

\begin{tabular}{lc}
\hline Network measures & $\mathbf{N}$. \\
Number of actors & 153 \\
Number of isolates & 125 \\
\hline Components & 126 \\
Component ratio & 0.822 \\
\hline Density & 0.004 \\
Degree of centralization & 0.082 \\
\hline Average degree & 0.627 \\
Fragmentation & 0.967 \\
\hline Dyad census & \\
$\quad$ Mutuals & 0.000 \\
$\quad$ Asymmetrics & 0.004 \\
Nulls & 0.996 \\
Reciprocity & 0.021 \\
\hline
\end{tabular}

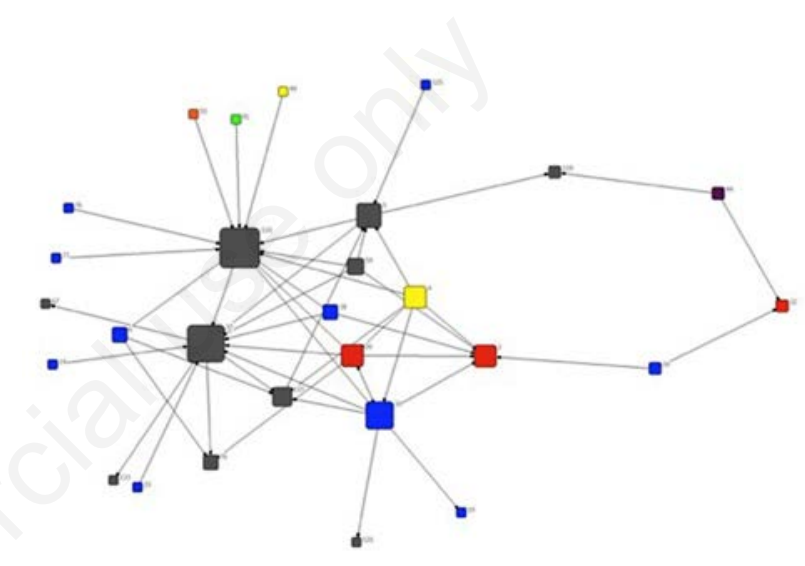

Figure 1. Visual overview of the network. Municipal support organizations shown in red, recreation organizations in yellow, healthcare organizations in blue, social support organizations in grey, educational organization in purple, housing organizations in orange, sport clubs in green.

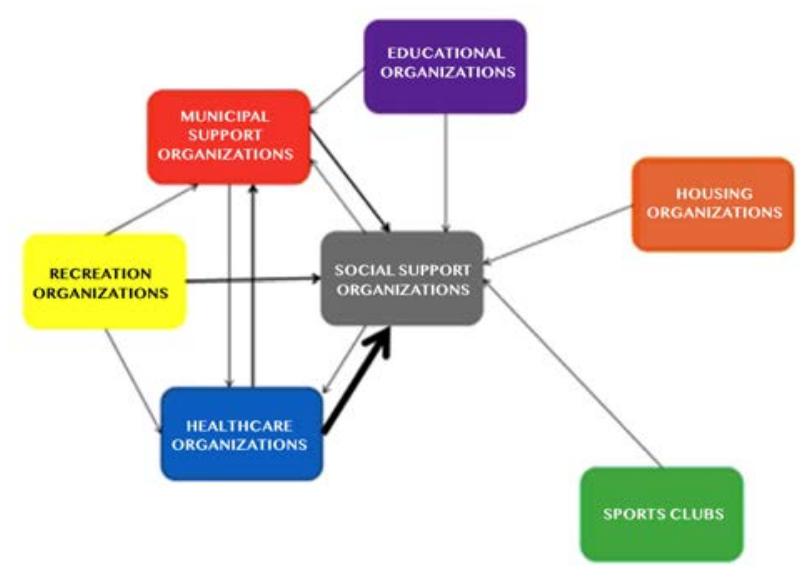

Figure 2. Connections between the different types of organizations. The narrowest arrows indicate one connection, the medium-thickness arrows indicate between 3 and 5 connections and the thickest arrow indicates 12 connections. 
gram provided them with a good overview of the current structure and organizations within the network. Most of them provided more information about the frequency and quality of their connections with other organizations after being presented with the network diagram. Nine interviewees mentioned that visualizing and explaining the network and conducting these participatory interviews would strengthen the network in the future, since they now saw opportunities to work together with other network organizations and felt encouraged to do so.

'I think this feedback is very important for us. When you actually see the network, you start to think differently about things. It makes you see which other parties you might talk to. Even this discussion brings us professionals closer together.'

\section{Connections between professional organizations}

Of the 17 interviewed professionals, 12 stated they appreciated the connection with other organizations. Two to three organizations were typically mentioned as close partners, and these organizations mostly worked in the same domain, e.g. healthcare or social support. After seeing the diagram, about half of the professionals said that their approach should become more multidisci- plinary. All interviewees mentioned that the connections between organizations could be enhanced and described the current network as under construction, part of a search process, starting up, fragmented and missing the connection with central organizations.

'On the whole, we collaborate closely with about three organizations, but that indicates there is still room for improvement. Well ... what you can see in this network is that each of us is working on the basis of their own vision and expertise. Things like "how can I solve this particular problem for this particular family? " But we also know that poverty is not the only problem involved, and that forces us to contact each other and try to collaborate.'

\section{Opportunities to strengthen the network}

The opinions and ideas of the interviewed professionals were explored, leading to six main themes. The theme that all interviewees agreed with was the need for an overview, which helps professionals to get to know each other and informs them about the support questions for which an organization can be contacted. Ten professionals also indicated the need for an intermediary person who adopts a managing role, who is aware of all the organizations in the network and serves as a general contact officer for all pro-

Table 3. Network measures for each organization.

\begin{tabular}{|c|c|c|c|c|c|c|c|}
\hline \multirow{2}{*}{$\begin{array}{l}\text { N. randomly assigned } \\
\text { to organizations }\end{array}$} & \multirow[t]{2}{*}{ Type of organization } & \multicolumn{6}{|c|}{ Actor measures } \\
\hline & & In-degree & Out-degree & $\begin{array}{l}\text { Degree } \\
\text { centrality }\end{array}$ & $\begin{array}{l}\text { Betweenness } \\
\text { centrality }\end{array}$ & $\begin{array}{l}\text { Average } \\
\text { reciprocal } \\
\text { distance }\end{array}$ & $\begin{array}{l}\text { Eigenvector } \\
\text { centrality }\end{array}$ \\
\hline 110 & Social support & 12.000 & 1.000 & 0.085 & 0.012 & 0.128 & $-0,593$ \\
\hline 37 & Social support & 8.000 & 4.000 & 0.078 & 0.010 & 0.124 & $-0,565$ \\
\hline 10 & Healthcare & 2.000 & 7.000 & 0.052 & 0.005 & 0.110 & $-0,476$ \\
\hline 5 & Social support & 4.000 & 3.000 & 0.046 & 0.006 & 0.107 & $-0,398$ \\
\hline 2 & Municipal support & 6.000 & 0.000 & 0.039 & 0.004 & 0.094 & -0.327 \\
\hline 20 & Municipal support & 2.000 & 5.000 & 0.039 & 0.001 & 0.104 & $-0,433$ \\
\hline 4 & Recreational & 0.000 & 6.000 & 0.039 & 0.001 & 0.102 & $-0,430$ \\
\hline 115 & Social support & 4.000 & 0.000 & 0.033 & 0.001 & 0.096 & $-0,344$ \\
\hline 59 & Social support & 0.000 & 4.000 & 0.026 & 0.001 & 0.098 & $-0,315$ \\
\hline 18 & Healthcare & 0.000 & 3.000 & 0.020 & 0.001 & 0.092 & $-0,248$ \\
\hline 70 & Social support & 3.000 & 0.000 & 0.020 & 0.000 & 0.084 & $-0,198$ \\
\hline 6 & Healthcare & 0.000 & 3.000 & 0.020 & 0.000 & 0.084 & $-0,190$ \\
\hline 119 & Social support & 2.000 & 0.000 & 0.013 & 0.002 & 0.075 & $-0,069$ \\
\hline 30 & Healthcare & 0.000 & 2.000 & 0.013 & 0.002 & 0.069 & $-0,057$ \\
\hline 44 & Educational & 0.000 & 2.000 & 0.013 & 0.001 & 0.061 & $-0,013$ \\
\hline 22 & Municipal support & 2.000 & 0.000 & 0.013 & 0.000 & 0.058 & $-0,012$ \\
\hline 76 & Healthcare & 0.000 & 1.000 & 0.007 & 0.000 & 0.075 & $-0,099$ \\
\hline 77 & Healthcare & 0.000 & 1.000 & 0.007 & 0.000 & 0.075 & $-0,099$ \\
\hline 91 & Sports club & 0.000 & 1.000 & 0.007 & 0.000 & 0.075 & $-0,099$ \\
\hline 49 & Recreational & 0.000 & 1.000 & 0.007 & 0.000 & 0.075 & $-0,099$ \\
\hline 55 & Housing & 0.000 & 1.000 & 0.007 & 0.000 & 0.074 & $-0,099$ \\
\hline 14 & Healthcare & 0.000 & 1.000 & 0.007 & 0.000 & 0.074 & $-0,094$ \\
\hline 23 & Healthcare & 0.000 & 1.000 & 0.007 & 0.000 & 0.074 & $-0,094$ \\
\hline 133 & Social support & 1.000 & 0.000 & 0.007 & 0.000 & 0.074 & $-0,094$ \\
\hline 67 & Social support & 1.000 & 0.000 & 0.007 & 0.000 & 0.074 & $-0,094$ \\
\hline 19 & Healthcare & 1.000 & 0.000 & 0.007 & 0.000 & 0.069 & $-0,080$ \\
\hline 121 & Social support & 1.000 & 0.000 & 0.007 & 0.000 & 0.069 & $-0,080$ \\
\hline 125 & Healthcare & 0.000 & 1.000 & 0.007 & 0.000 & 0.068 & $-0,067$ \\
\hline
\end{tabular}


fessionals involved in the support of low-SES persons. Nine participants mentioned that greater awareness of the current low-SES issues was needed among professionals, especially concerning the links between different domains. Eight interviewees stated that more support was especially needed to ensure that issues are identified at an early stage, and three organizations actually wanted support to enable them to pick up signals when these low-SES citizens experienced problems. Finally, five organizations, mostly social support organizations, also specified that more capacity was needed.

'What I notice a lot is that we don't know each other's position, that we don't know the challenges faced by the other organizations, so we don't know what we can contact the others about. Even just knowing what organizations there are and what each of them is doing would benefit us a lot.'

\section{Phase 3: Networking session}

A total of 35 professionals, who had also participated in the SNA, attended the networking session. Attendants were asked to choose the dimension they mostly worked in. The majority of the professionals opted for the 'participation' domain. They mentioned that they only knew one or two of the professionals who had opted for the same dimension, while the others were new to them. The same happened among the participants within the other domains.

Following a plenary presentation of Figure 1, the participants were asked how they would like to improve the strength of the network. As a first step, all of them agreed that there should be a central information location offering an overview of all organizations, probably online. The importance of an up-to-date database was noted, including all organizations, with a brief explanation of their activities and of the support questions for which they could be contacted.

\section{Discussion and Conclusions}

Low-SES populations are often hidden in society. The current study examined the value of using network analysis as a tool to improve the reach of low SES populations and in harmonizing and enhancing their service delivery.

Although the issue of socioeconomic health problems among low-SES populations is receiving a lot of professional attention, our research showed that the service delivery structures and the ability to reach low-SES people still needs improvement. ${ }^{3,7,32}$ The SNA showed that low-SES people were seen by at least 50 different professional organizations within a relatively small municipality, implying that there are many organizations which are in touch with these citizens, but in a highly fragmented manner. One important precondition for integrated approaches to reduce socioeconomic health inequalities is that professionals connect with organizations from other domains. Low-SES populations often have multiple issues, e.g. physical health, mental health and lack of participation, which means that well-coordinated, multidisciplinary support is needed ${ }^{33}$ Yet only $18 \%$ of the professional organizations in our study indicated that they were in contact with other organizations, while merely five organizations $(3 \%)$ both reached and referred low-SES citizens. This implied a weak network structure, with many isolated organizations and a low score for connectedness. When organizations did connect, it was mostly with organizations working in the same domain. It is unlikely that this network structure is able to deliver an integrated and comprehensive care package to low-SES individuals. ${ }^{18}$

After completing the SNA, we held interviews with 17 key employees of central organizations to assess how professionals perceived the connections and what options they saw to improve the current network structure. Most professionals indicated that connections with other domains were difficult or that they had not even considered this before. It was interesting to observe that the professionals started explaining more about the quality of their network and connections with organizations after the network had been visualized for them. New insights emerged after they realized how wide the network was. Most of the professionals seemed to alter their mind-set, opening up to a broader picture of their field of work in order to tackle the multiple problems of low-SES populations. As a result, they said they would now be more open to finding connections with organizations within their own health domain as well as outside the health domain to find connections related to the social determinants of health inequalities, such as finance, education and labour. More than half of the interviewees mentioned that visualizing and discussing the network had given them new ideas for future connections with other organizations. This is likely to improve the quality of the service delivery network for low-SES populations.

Finally, the interviews were followed up by a joint networking session with all relevant stakeholders. The aim was to put good intentions into practice, which was facilitated by the professionals meeting each other in person. During the networking session, the attendees were struck by the fact that they knew so few of the other professionals working in care delivery services for low-SES populations, even those who were working in their own domain. Most organizations saw participation as an important dimension of their work, but mostly from their point of view, without including other organizations. Eventually, all professionals who participated in the interviews and the networking session agreed that the network should be strengthened, and that the first step should be to improve their understanding of each other. They concluded that all organizations should be mapped in a central up-to-date database, each with a brief explanation of their activities to support low-SES populations. $^{34}$

\section{Strengths and limitations}

A strength of this network study was the participatory nature of the research, including the cooperation of the municipal authorities of Vaals and organizations working in Vaals. The response rate of the different types of organizations was good. It seems that although the response was self-selected by the organizations, participation occurred proportionally in all organizational types. All organizations of the housing and municipal support type participated in the research, which were relatively small groups. Only one educational organization did not respond (response $80 \%$ ). For the other types of organizations, mostly containing a larger number of organizations, about 5 to 17 organizations did not participate, indicating a response of at least $60 \%$ for each organizational type in the SNA. Furthermore, the willingness of the most central organizations to participate in the interviews in phase 2 was helpful in providing an accurate overview of the current network structure and possibilities for improvement, leading to a high level of data saturation since the final interviews no longer provided new information. ${ }^{35}$ Difficulties regarding service delivery for low-SES populations due to weak network structures are a common phenomenon, which makes these results useful for other regions as well.

In addition, some limitations should be acknowledged. First, not all organizations filled in the questionnaire. These organizations were included in the analyses as missing. In practice, the network might thus be somewhat stronger than the current analysis indicated. However, all participating organizations were asked to indicate their connections with other organizations. This meant 
that data on non-participating organizations could still be obtained indirectly, making the network more accurate. The use of an online questionnaire and interviews might have caused some incorrect answers due to information bias, since professionals could both overestimate their connections or forget some organizations. ${ }^{36,37}$

\section{Recommendations for future research and practice}

The current network structure among professionals supporting low-SES populations in the municipality of Vaals, the Netherlands, could be defined as weak. Visualizing and discussing the network with the professionals was found to be useful in obtaining greater insights into the perceived quality of mutual connections and identifying opportunities to strengthen the network. A major problem that was acknowledged by all professionals was the lack of a clear overview of all support services and arrangements that were available. In future practice, greater emphasis should be placed on developing a central up-to-date database, with a brief explanation of the main activities or domains by which each organization supports low-SES individuals, in order to inform other organizations what referral options they have. In addition, an intermediary person or an organization acting as network administrator, who would be responsible for managing this system, would be helpful to strengthen the current structure. ${ }^{38}$ The municipal authorities of Vaals have already indicated that they wanted to address these points for improvement in the near future.

The use of SNA as a tool to gain more in-depth insights and richer information regarding the relations within a network proved to be feasible and useful, and we recommend its use in future research. The processes occurring in the network in the municipality of Vaals will also be followed up in continued participatory research, to enable us to define the effects of the actions taken by the municipal authorities to improve the connections between organizations supporting low-SES populations. ${ }^{39,40}$

Correspondence: Lotte Prevo, NUTRIM School of Nutrition and Translational Research in Metabolism, Department of Health Promotion, Faculty of Health, Medicine \& Life Sciences, Maastricht University, Postbus 6166200 MD Maastricht, The Netherlands.

Tel.: +31.43.388.2416.

E-mail: l.prevo@maastrichtuniversity.nl

Key words: social network analysis, service delivery, low socioeconomic status populations, service organizations.

Contributions: LP: design of the work, data collection, data analysis and interpretation, drafting the article, final approval; LM design of the work, data analysis and interpretation, critical revision of the article, final approval; MJ, SK, design of the work, data analysis and interpretation, critical revision of the article, final approval.

Conflict of interest: the authors declare no potential conflict of interest.

Funding: none.

Received for publication: 8 February 2018.

Revision received: 23 May 2018.

Accepted for publication: 24 May 2018.

CC Copyright L. Prevo et al., 2018

Licensee PAGEPress, Italy

Journal of Public Health Research 2018;7:1369

doi:10.4081/jphr.2018.1369

This work is licensed under a Creative Commons Attribution NonCommercial 4.0 License (CC BY-NC 4.0).

\section{References}

1. Cosgrove S. Poverty, Health and Participation. Irish Med J 2007;100:73-5.

2. Mullins CD, Blat L, Gbarayor CM, et al. Health disparities: A barrier to high-quality care. Am J Health System Pharmacy. 2012;62:1873-82.

3. Marmot M, Allen J, Bell R, et al. WHO European review of social determinants of health and the health divide. Lancet 2012;380:1011-29.

4. Habib B, Narayan A, Olivieri S, Sanchez-Paramo C. The impact of the financial crisis on poverty and income distribution: Insights from simulations in selected countries. 2010 [Cited 2017 Dec 04]. Available from: http://voxeu.org/article/ impact-financial-crisis-poverty-and-income-distributions

5. Neckerman KM, Torche F. Inequality: Causes and Consequences. Ann Rev Sociol 2007;33:335-57.

6. Bor J, Cohen GH, Galea S. Population Health in an era of rising income inequality. Lancet 2017;389:1475-90.

7. Wilkinson R, Pickett K. The Spirit Level: why more equal societies almost always do better. London: Penguin; 2009.

8. Fund NutsOhra. [Background Information of the Program a Closer Healthy Future]. 2015 [Cited 2018 May 15]. Available from: https://www.fnozorgvoorkansen.nl/wpcontent/uploads/2014/12/Achtergrond-Gezonde-ToekomstDichterbij.pdf

9. Boshuizen HC, Nusselder WN, Peters F, Verweij A. [Indexing differences in healthy life expectations among SES groups]. Bilthoven: RIVM; 2014.

10. Marmot M, Allen J. Social Determinants of Health Equity. Am J Public Health 2014:104;s517-9.

11. Mullainathan S, Shafir E. Scarcity: Why having too little means so much. New York: Henry Holt \& Company LLC; 2013.

12. Salomon JA, Wang H, Freeman MK, et al. Healthy life expectancy for 187 countries, 1990-2010: a systematic analysis for the Global Burden Disease Study 2010. Lancet 2012;380:2144-62.

13. Chetty R, Stepner M, Abraham S, et al. The Association Between Income and Life Expectancy in the United States, 2001-2014. JAMA 2016;315:1750-66.

14. Makaroun LK, Brown RT, Diaz-Ramirez LG, et al. WealthAssociated Disparities in Death and Disability in the United States and England. JAMA Internal Med 2017:E1-E9.

15. Pampel FC, Krueger PM, Denney JT. Socioeconomic Disparities in Health Behaviors. Ann Rev Sociol 2010;36:34970.

16. Bosma H, Jansen M, Schefman S, et al. Lonely at the bottom: a cross-sectional study on being ill, poor, and lonely. Public Health 2015;129:185-7.

17. Evans GW. Childhood poverty and adult psychological wellbeing. PNAS 2016:113;14949-52.

18. World Health Organization. Strengthening Health Systems to Improve Health Outcomes. 2007 [Cited may 22] Available from: http://apps.who.int/iris/bitstream/handle/10665 /43918/9789241596077_eng.pdf;jsessionid=88FBF43E19886 A1D600182A6BAE76429? sequence $=1$

19. Sociaal-Economische Raad. [Growing up without poverty]. Den Haag: Sociaal-Economische raad; 2017.

20. Bonevski B, Randell M, Paul C, et al. Reaching the hard-toreach: a systematic review of strategies for improving health and medical research with socially disadvantaged groups. BMC Med Res Methodol 2014;14:1-29.

21. Oude Vrielink M, Koper H, Sterrenberg L. [One family, one 